\title{
Measuring the Brittle-to-Ductile Transition Temperature of Tungsten- Tantalum Alloy using Chevron-Notched Micro-Cantilevers
}

\author{
B-S. Li, T.J. Marrow, D.E.J. Armstrong \\ bo-shiuan.li@materials.ox.ac.uk \\ Department of Materials, University of Oxford, Oxford OX1 3PH, United Kingdom
}

\begin{abstract}
High-temperature micro-fracture tests of an industrial grade $\mathrm{W}-1 \%$ Ta alloy were performed from room temperature up to $700{ }^{\circ} \mathrm{C}$, using chevron-notched micro-cantilevers. A gradual increase of conditional fracture toughness $\left(\mathrm{K}_{\mathrm{Qc}}\right)$ was measured with increasing temperature, and a microscale brittle-to-ductile transition temperature (BDTT) was found at $\sim 600{ }^{\circ} \mathrm{C}$. This is slightly higher than macroscopic three-point bending tests from the same material ( 400 ${ }^{\circ} \mathrm{C}$ ), and contradicts most literatures for pure tungsten that shows a significant lower microBDTT. The results suggested that the BDTT is independent of the specimen size, and the higher micro-BDTT is due to the tantalum in this alloy.

\section{Keywords: Micro-fracture tests; high-temperature micromechanics; BDTT; crack tip plasticity; tungsten alloy}

Micro-fracture testing using notched cantilevers is now an established technique for measuring the fracture properties at the microscale, utilising focused-ion beam (FIB) milling to fabricate micro-specimens and nanoindentation to apply load [1-4]. However, most reported studies were performed at room temperature; knowledge of the material's performance under realistic operating conditions is also required. Tungsten-based alloys, which are primary candidate materials for the divertor of a inertial-confinement nuclear fusion reactor, are envisaged to operate under intense neutron irradiation and extremely high temperatures [5]. Due to limited access to high energy and high flux neutron sources and the challenges of examining radioactive materials, ion irradiation is often used as a surrogate for neutron irradiation in screening studies and also for investigations of the fundamental effects of lattice defects on mechanical properties. The major drawback is that ion irradiation only produces damage near the irradiated surface (from a depth of few hundreds of nm to a few $\mu \mathrm{m})$, making micromechanical testing the only suitable technique for extracting mechanical properties. The challenge is thus to conduct micro-fracture tests in ion-irradiated samples at 
fusion-relevant temperatures so that fracture properties, including fracture toughness, and the brittle-to-ductile transition temperature (BDTT), can be measured.

The fracture properties of tungsten are influenced by both intrinsic factors (single grain or poly-crystal, impurities, grain size) and extrinsic factors (strain-rate, temperature). Some of these influences may become more pronounced when reducing the specimen size to the micrometre regime. Ast et al. [6] conducted notched micro-cantilever fracture tests of single-crystal tungsten from $-90{ }^{\circ} \mathrm{C}$ to $500{ }^{\circ} \mathrm{C}$, showing brittle cleavage-like fracture at lower temperatures, with progressively more ductile behaviour with increasing temperatures. They reported a BDTT between $21^{\circ} \mathrm{C}$ and $75^{\circ} \mathrm{C}$, which is considerably lower compared to the macroscopic value $\left(120 \sim 250^{\circ} \mathrm{C}\right)$ for high-purity single crystal tungsten reported by Giannattasio et al. [7]. Ast proposed that the lower BDTT was due to the micrometre specimen size. They also reported an activation energy for the BDT of $0.36 \mathrm{eV}$, similar to the value of activation energy reported for macroscopic single-crystal tungsten by Gumbsch et al. $(0.2 \mathrm{eV})[8]$, where the specimen orientation was such as to favour crack-tip plasticity controlled by glide of edge dislocations. These values are significantly lower than the activation energy for the BDT in macroscopic single crystal and polycrystalline tungsten reported by Giannattasio et al. $(1.05 \mathrm{eV})$ [7, 9, 10]; this was associated with crack-tip plasticity controlled by kink-pair formation on screw dislocations, which is more generally the case for plasticity in tungsten and other BCC metals [11].

High temperature micro-fracture tests were performed on pre-notched single crystal silicon cantilevers by Jaya et al. [12]. They reported a gradual transition from brittle to ductile failure, and reported a BDTT of around $300{ }^{\circ} \mathrm{C}$, which is also considerably lower than the macroscopic transition temperatures reported by Samuels et al. of $560 \sim 600^{\circ} \mathrm{C}$ (varying with strain rate) using four-point bending of pre-cracked specimens [13], and lower than the value of $600{ }^{\circ} \mathrm{C}$ reported by Armstrong et al. for un-notched micro-cantilever beams [14]. Jaya et al. proposed that the reduction of BDTT was due to the pronounced dislocation activity induced by the stress concentration at the crack tip. Similarly, Hintsala et al. [15] performed micro-fracture tests on silicon from room temperature to $600{ }^{\circ} \mathrm{C}$, using notched doubleclamped beams, and both fracture toughness and fracture initiation load were observed to increase with increasing temperature. TEM observations of tested specimens showed dislocations propagated from the crack tip at temperatures above $450{ }^{\circ} \mathrm{C}$, and it was proposed that the dislocation shielding at the crack tip due to the generation of back stresses was responsible for the lower BDTT in these micro-specimens. 
The literature thus shows a general trend for micro-fracture tests to report a lower BDT temperature (micro-BDTT) compared to larger specimens (macro-BDTT) of the same material, implying that plasticity at the crack tip has a greater effect at lower temperatures in micro-scale specimens. However, downscaling the specimen size to the micrometre regime shouldn't affect the elastic stress concentration at the crack tip, and whether this has an influence on the plastic stress concentration (from dislocation motion) is still yet unclear. Moreover, all the micro-BDTT experiments reported to date were performed on model systems, i.e. high purity single-crystal specimens, with a well-defined crack system. In engineering alloys, the pre-existing dislocation network and dislocation interactions with grain boundaries, precipitates, and impurities all strongly affect the BDTT [7-9]. In this work, chevron-notched micro-cantilevers of an industrial-grade polycrystalline $\mathrm{W}-1 \%$ Ta alloy were tested between $25^{\circ} \mathrm{C}$ and $700^{\circ} \mathrm{C}$. The conditional fracture toughness at crack instability $\left(\mathrm{K}_{\mathrm{Qc}}\right)$ at each temperature was calculated, and is compared with the macroscopic fracture toughness $\left(\mathrm{K}_{\mathrm{Ic}}\right)$ from larger three-point bend specimens. The aim was to determine whether a sample size effect exists for the BDTT in an engineering alloy that contains grain boundaries and impurities.

The industrial grade tungsten-1wt $\%$ tantalum alloy (W-1\% Ta) was produced by Plansee ${ }^{\circledR}$ (Reutte, Austria) via powder consolidation and hot forging. Shown in Fig. 1, the grains as seen in the S-T orientation were elongated along the short-transverse (S) direction due to the hot forging. Grain radius is approximately $\sim 30 \mu \mathrm{m}$ along the L-S orientation, and approximately $1.5 \mu \mathrm{m}$ along the $\mathrm{S}$-T orientation. The grains as seen in the L-S orientation are much more equiaxed and have an average radius of approximately $38 \mu \mathrm{m}$. Micro-cantilevers were fabricated on the S-T orientation so that deformation behaviour is more representative of a polycrystalline sample. Although tungsten is widely-considered as an elastically isotropic material, but both plastic deformation and fracture is anisotropic [18]. The comparison between a single crystal $\mathrm{W}$ and polycrystalline $\mathrm{W}-1 \%$ Ta micro-cantilevers at room temperature is shown in the Supplementary Materials, which clearly demonstrates that mechanical response can differ significantly depending on how many grains (or grain boundaries) were included in the micro-cantilever.

The chevron-notched micro-cantilever design was selected due to its crack stability which is suitable for elastic-plastic fracture mechanical (EPFM) analysis. A dual-beam Zeiss ${ }^{\circledR}$ Auriga FIB/SEM was used to fabricate pentagonal cross-section micro-cantilevers on the polished surface of a single sample of $\mathrm{W}-1 \% \mathrm{Ta}$, and to introduce a chevron notch into each 
cantilever near the fixed end. All cantilevers had length (L) around $11 \mu \mathrm{m}$, thickness (B) and width (W) about $3 \mu \mathrm{m}$; the actual dimensions of the individual cantilevers were measured and used in the subsequent analyses. The chevron notches had a tip depth $\left(\mathrm{a}_{0}\right)$ ranging from 0 to $0.3 \mu \mathrm{m}$, and base depth $\left(\mathrm{a}_{1}\right)$ ranging from 2.1 to $2.7 \mu \mathrm{m}$. Details of the cantilever fabrication and chevron notch optimisation were described in previous work by Li et al. [19]. SEM images and EBSD maps of the five tested cantilevers are shown in Fig. 1.

High-temperature cantilever bending was performed using a Micro Materials NanoTest ${ }^{\mathrm{TM}}$ Xtreme nanoindenter (Wrexham, UK) equipped with a cubic boron nitride Berkovich tip. The nanoindenter is inside a chamber that achieves a vacuum level of $\sim 10^{-6}$ mbar to prevent oxidation. The $\mathrm{W}-1 \%$ Ta sample was mounted on a heating stage using OMEGABOND $^{\mathrm{TM}} 600$ thermal conductive cement, and was heated from room temperature to $400{ }^{\circ} \mathrm{C}, 500{ }^{\circ} \mathrm{C}, 600{ }^{\circ} \mathrm{C}$, and $700{ }^{\circ} \mathrm{C}$ consecutively at a constant rate of $1.6{ }^{\circ} \mathrm{C} / \mathrm{min}$.

Temperature matching of the sample and indenter were conducted prior to each test to within $1{ }^{\circ} \mathrm{C}$ in order to minimise thermal drift. Test results at intermediate temperatures (RT to 400 ${ }^{\circ} \mathrm{C}$ ) were disregarded, due to premature failure of cantilevers from the AFM-like scanning (to provide a topological map for precise positioning). Then, the cantilevers were loaded to introduce stable crack growth followed by unstable fracture using a progressive load partialunload method described by Li et al. [19]. Quasi-static stiffness values were measured from the mid-50\% of the unloading curve in every load partial-unload cycle, and were used for crack length calculations. Test parameters for the five tested cantilevers are shown in Table I.

\begin{tabular}{ccccccc}
\hline Temperature & $\begin{array}{c}\text { Load/Unload } \\
\text { Rate }\end{array}$ & $\begin{array}{c}\text { Load } \\
\text { Increment }\end{array}$ & Hold & $\begin{array}{c}\text { \% to } \\
\text { Unload }\end{array}$ & $\begin{array}{c}\text { Fracture } \\
\text { Initiation Load Instability Load }\end{array}$ & $\begin{array}{c}\text { Fracture } \\
25^{\circ} \mathrm{C}\end{array}$ \\
\hline $10 \mu \mathrm{N} / \mathrm{s}$ & $50 \mu \mathrm{N}$ & $20 \mathrm{sec}$ & $50 \%$ & $250 \mu \mathrm{N}$ & $800 \mu \mathrm{N}$ \\
$400^{\circ} \mathrm{C}$ & $10 \mu \mathrm{N} / \mathrm{s}$ & $50 \mu \mathrm{N}$ & $20 \mathrm{sec}$ & $50 \%$ & $200 \mu \mathrm{N}$ & $600 \mu \mathrm{N}$ \\
$500^{\circ} \mathrm{C}$ & $10 \mu \mathrm{N} / \mathrm{s}$ & $50 \mu \mathrm{N}$ & $20 \mathrm{sec}$ & $50 \%$ & $100 \mu \mathrm{N}$ & $539 \mu \mathrm{N}$ \\
$600{ }^{\circ} \mathrm{C}$ & $10 \mu \mathrm{N} / \mathrm{s}$ & $50 \mu \mathrm{N}$ & $20 \mathrm{sec}$ & $50 \%$ & $200 \mu \mathrm{N}$ & $450 \mu \mathrm{N}$ \\
$700^{\circ} \mathrm{C}$ & $10 \mu \mathrm{N} / \mathrm{s}$ & $50 \mu \mathrm{N}$ & $20 \mathrm{sec}$ & $50 \%$ & $200 \mu \mathrm{N}$ & $419 \mu \mathrm{N}$ \\
\hline
\end{tabular}

Table I Test parameters for the five cantilevers tested from 25 to $700{ }^{\circ} \mathrm{C}$. The percentage to unload indicates the cantilevers were loaded first, then partial-unloaded to $50 \%$ of the maximum load in each cycle

Fig. 2(a) shows the thermal drift corrected load-displacement curves for the five cantilevers tested from 25 to $700{ }^{\circ} \mathrm{C}$. As the test temperature increased, a decrease in the 
yield load and an increase in the displacement to failure were observed. The amount of stable crack growth (SCG) prior to unstable fracture for each cantilever are shown in Fig. 2(b). This was obtained using the quasi-static unloading stiffness from each cycle, which can be related to the cantilever stiffness from the FE models of incremental crack length. The measured SCG tended to increase with temperature, except for the $500{ }^{\circ} \mathrm{C}$ cantilever, due to a weak grain boundary along the crack path. Full details of the analysis method employed to quantify the SCG are described by Li et al. [19].

Post-test SEM images of cantilevers tested at the upper and lower temperatures (25 ${ }^{\circ} \mathrm{C}, 600{ }^{\circ} \mathrm{C}$ and $700{ }^{\circ} \mathrm{C}$ ) are shown in Fig. 3(a,c,e). Fracture occurred catastrophically at the end of the test for both the $25^{\circ} \mathrm{C}$ and $600{ }^{\circ} \mathrm{C}$ cantilevers, evidenced by the loosely attached free ends. The cantilevers tested at intermediate temperatures $\left(400{ }^{\circ} \mathrm{C}\right.$ and $500{ }^{\circ} \mathrm{C}$, not shown here) showed similar fracture behaviour. In contrast, fracture was more stable for the $700{ }^{\circ} \mathrm{C}$ test, and cantilever remained mostly attached after testing. The cantilevers were removed using a micromanipulator within the SEM to allow the fracture surface to be examined Fig. 3(b,d,f). Ductile fracture features were observed at the upper region of the chevron ligament, with brittle cleavage-like features dominating the lower region of the fracture plane. The extent of the ductile region (highlighted by red-dotted line) agrees with the size of the SCG region estimated from the unloading stiffness measurements (Fig. 2(b)). Both loaddisplacement curves and fractography provided strong evidence that the SCG is associated with plasticity, and its extent increased with increasing temperature.

The conditional fracture toughness for crack initiation, $\mathrm{K}_{\mathrm{Qi}}$ and crack instability, $\mathrm{K}_{\mathrm{Qc}}$, were calculated using the fracture initiation and instability load, given in Table $\mathbf{1}$ and the EPFM approach described previously [19], and are plotted as function of temperature in Fig. 4. Although a drop of yield load was clearly observed with increasing temperature (Fig 2), the initiation toughness remained constant $\left(\sim 2 \mathrm{MPa} \cdot \mathrm{m}^{0.5}\right)$, whereas the instability toughness increased gradually with temperature. The difference observed between $\mathrm{K}_{\mathrm{Qi}}$ and $\mathrm{K}_{\mathrm{Qc}}$ suggests crack tip shielding occurred during stable crack extension, due to the increased crack tip plasticity. A sharp increase of $\mathrm{K}_{\mathrm{Qc}}$ was observed at $700{ }^{\circ} \mathrm{C}$, suggesting a micro-BDTT between 600 and $700{ }^{\circ} \mathrm{C}$. This is supported by the fractography in Fig. 3. Data from macroscopic three-point bending fracture tests of the same $\mathrm{W}-1 \% \mathrm{Ta}$ alloy performed by 
Wurster et al. [20] are shown for comparison. These show a progressive increase of fracture toughness with temperature, from $\sim 5 \mathrm{MPa} \cdot \mathrm{m}^{0.5}$ at $25^{\circ} \mathrm{C}$ to $\sim 13 \mathrm{MPa} \cdot \mathrm{m}^{0.5}$ at $600{ }^{\circ} \mathrm{C}$, and a gradual BDT at temperature above $450{ }^{\circ} \mathrm{C}$. The microscopic $\mathrm{K}_{\mathrm{Qc}}$ were significantly higher than the macroscopic $\mathrm{K}_{\mathrm{Ic}}$; this is because EPFM analysis assumes all plastic work contributed to the creation of new crack surfaces. However, the plastic work includes redundant energy dissipation through plastic deformation (such as the formation of a plastic hinge in the small specimen ligament). In addition, the larger crack tip plastic zone to specimen size ratio would also contribute to the higher microscopic $\mathrm{K}_{\mathrm{Qc}}$. Applying Irwin's estimation in Eq. 1, the estimated crack tip plastic zone at room temperature is about $1.2 \mu \mathrm{m}$ (using macroscopic $\mathrm{K}_{\mathrm{Ic}}$ of $5 \mathrm{MPa} \cdot \mathrm{m}^{0.5}$, and $\sigma_{\mathrm{ys}}$ of $1.8 \mathrm{GPa}$ ). This is comparable to the cantilever thickness used in this work $(\sim 3 \mu \mathrm{m})$. Increasing the test temperature will further extend the crack tip plastic zone size, hence, the $\mathrm{K}_{\mathrm{Qc}_{\mathrm{c}}}$ reported here should only serve as the higher bound fracture toughness values.

$$
r_{y}=\frac{1}{2 \pi}\left[\frac{K}{\sigma_{Y S}}\right]^{2}
$$

Crack path in Wurster's macroscopic tests can travel through multiple grains and grain boundaries, which can be the reason for their lower fracture toughness since fracture will occur unstably when encountering a weak grain boundary or cleavage plane. In most microcantilever tests, crack path should only travel through a single grain (except for the $500{ }^{\circ} \mathrm{C}$ test), hence the higher microscopic $\mathrm{K}_{\mathrm{Qc}}$ reported are more likely to due to a specimen size effect described previously.

Hirsch et al. showed that dislocation-driven stable crack growth (SCG) can occur in semi-brittle materials, and the extent for such SCG is expected to increase with temperature due to enhanced dislocation mobility [21]. In this study, SCG was observed at all temperatures. Due to the polycrystalline nature and high initial dislocation density of this engineering alloy microstructure, it is extremely difficult to visualise individual slip traces by fractography. The fracture surfaces, on the other hand, showed strong evidence of ductility, including extensive 
dimple-like features and river-like patterns at the transition from SCG to the unstable fracture crack front, which is consistent with plasticity being concurrent with SCG.

The BDTT $\left(\sim 600^{\circ} \mathrm{C}\right)$ measured here is significantly higher than the BDTT (150 250 ${ }^{\circ} \mathrm{C}$ ) reported by Gianattasio et al. [9] from large pre-cracked polycrystalline tungsten matchsticks tested by 4-point bending and that of Ast et al. [6] from notched single-crystal tungsten micro-cantilevers. It is also slightly higher than the BDTT $\left(\sim 450{ }^{\circ} \mathrm{C}\right)$ reported by Wurster et al. [20] from macroscopic pre-cracked 3-point bending fracture testsof the same polycrystalline W-1\%Ta. Murphy et al. [16] discussed some effects of impurities on the BDTT of tungsten, reporting that CVD-grown tungsten was brittle throughout the entire test temperature range $\left(25 \sim 967{ }^{\circ} \mathrm{C}\right)$ due to the segregation of fluorine impurities that embrittled the grain boundaries. Also shown in the Supplementary Material, the W-1\% Ta microcantilever is much more brittle compared to the single-crystal micro-cantilever. This demonstrated that the tantalum addition not only hinders dislocation motion but also embrittles the grain boundaries [22]. It is therefore possible that the Ta addition pushed the micro-BDTT higher than Wurster's macro-BDTT.

The effects of strain rate on the BDTT of single crystal tungsten was discussed by Roberts and Tarleton et al. [7]; they reported that the BDTT increases with increasing strain rate, with an activation energy identical to that of dislocation glide, as expressed in Eq. 2

$$
\dot{\varepsilon}=\exp \left(-\frac{U}{k T_{B D T}}\right)(\boldsymbol{E q} \cdot \mathbf{2})
$$

where $\dot{\varepsilon}$ is the strain rate, $\mathrm{A}$ is a constant, $\mathrm{U}$ is the activation energy for dislocation glide $(1.05 \pm 0.05 \mathrm{eV}$ for screw dislocation glide as it controls the bulk plasticity of tungsten), $\mathrm{k}$ is the Boltzmann constant, $\mathrm{T}_{\mathrm{BDT}}$ is the brittle-to-ductile transition temperature

The strain rate in their macroscopic 4-point bending tests was around $4 \times 10^{-5} \mathrm{~s}^{-1}$, and a BDTT between $150{ }^{\circ} \mathrm{C}$ to $250{ }^{\circ} \mathrm{C}$ was observed. The experiments in this work were conducted using load-controlled nanoindenter, therefore, constant strain rate was only maintained in the elastic regime; non-linear deformation, such as plasticity and fracture, causes the indenter to increase the strain rate. Consequently, the strain rate in the microcantilever tests ranged from $10^{-3}$ (in the elastic regime) to approximately $5 \times 10^{-2} \mathrm{~s}^{-1}$ (in the plastic/fracture regime), which is significantly higher than Roberts and Tarleton et al. [7]. Assuming the same activation energy, extrapolating the data of Gianatiassio et al. to the highest strain rate of the microcantilever tests $\left(\sim 5 \times 10^{-2} \mathrm{~s}^{-1}\right)$ would give a BDTT of $\sim 300^{\circ} \mathrm{C}$, 
which is much lower than the observed microscopic value of $600-700{ }^{\circ} \mathrm{C}$. Therefore, it is proposed that the tantalum addition in the polycrystalline tungsten, together with the higher strain rate used, are the dominant factors for the higher BDTT that is observed in the microscale experiments.

In summary, high-temperature micro-fracture tests of chevron-notched polycrystalline $\mathrm{W}-1 \%$ Ta micro-cantilevers were carried out at temperatures between $25^{\circ} \mathrm{C}$ and $700{ }^{\circ} \mathrm{C}$. The amount of ductile stable crack growth (SCG) increased with temperature, and it is suggested that SCG is a dislocation-driven process. The conditional fracture toughness for crack instability $\left(\mathrm{K}_{\mathrm{Qc}}\right)$, calculated using an EPFM approach, gradually increased with temperature up to $600{ }^{\circ} \mathrm{C}$, then increased significantly at $700{ }^{\circ} \mathrm{C}$, which indicates a micro-BDTT between 600 and $700{ }^{\circ} \mathrm{C}$. This BDTT is significantly higher than values reported for single crystal and polycrystalline tungsten (typically $150-250{ }^{\circ} \mathrm{C}$ ), but is comparable to that measured in macroscopic specimens of the same polycrystalline $\mathrm{W}-1 \% \mathrm{Ta}$ alloy. It is concluded that the higher-BDTT of industrial grade tungsten alloys is due to the tantalum addition, and possibly also to their more complex microstructure. High-temperature micro-fracture tests can provide an upper-bound estimate of the BDTT, and may therefore find applications in the testing of ion-irradiated materials that require such micro-scale mechanical tests.

\section{ACKNOWLEDMENTS}

B.-S. Li and D.E.J. Armstrong would like to acknowledge EPSRC Platform Grant EP/P001645/1, and project grants EP/R006245/1 and EP/R021775/1 for the financial support. The authors would also like to thank Prof. Steve Roberts for his valuable discussions.

\section{References}

[1] D. Di Maio and S. G. Roberts, "Measuring fracture toughness of coatings using focused-ion-beam-machined microbeams,” J. Mater. Res., vol. 20, no. 2, pp. 299-302, 2005 .

[2] K. Matoy, T. Detzel, M. Müller, C. Motz, and G. Dehm, "Interface fracture properties of thin films studied by using the micro-cantilever deflection technique," Surf. Coatings Technol., vol. 204, no. 6-7, pp. 878-881, 2009.

[3] D. E. J. Armstrong, A. J. Wilkinson, and S. G. Roberts, "Micro-mechanical measurements of fracture toughness of bismuth embrittled copper grain boundaries," Philos. Mag. Lett., vol. 91, no. 6, pp. 394-400, 2011. 
[4] S. Wurster, C. Motz, and R. Pippan, "Characterization of the fracture toughness of micro-sized tungsten single crystal notched specimens," Philos. Mag., vol. 92, no. January 2014, pp. 1803-1825, 2012.

[5] S. J. Zinkle and N. M. Ghoniem, "Operating temperature windows for fusion reactor structural materials," Fusion Eng. Des., vol. 52, no. 2000, pp. 55-71, 2008.

[6] J. Ast et al., "The brittle-ductile transition of tungsten single crystals at the microscale," Mater. Des., vol. 152, pp. 168-180, 2018.

[7] A. Giannattasio and S. G. Roberts, "Strain-rate dependence of the brittle-to-ductile transition temperature in tungsten," Philos. Mag., vol. 87, no. 17, pp. 2589-2598, Jun. 2007.

[8] P. Gumbsch, P. Gumbsch, J. Riedle, A. Hartmaier, and H. F. Fischmeister, "Controlling Factors for the Brittle-to-Ductile Transition in Tungsten Single Crystals," vol. 1293, no. 1998, 2013.

[9] A. Giannattasio, Z. Yao, E. Tarleton, and S. G. Roberts, "Brittle - ductile transitions in polycrystalline tungsten," vol. 6435, 2010.

[10] E. Tarleton and S. G. Roberts, "Dislocation dynamic modelling of the brittle-ductile transition in tungsten," Philos. Mag., vol. 89, no. 31, pp. 2759-2769, Nov. 2009.

[11] C. R. Weinberger, B. L. Boyce, and C. C. Battaile, "Slip planes in bcc transition metals," Int. Mater. Rev., vol. 58, no. 5, pp. 296-314, Jun. 2013.

[12] B. N. Jaya et al., "Microscale Fracture Behavior of Single Crystal Silicon Beams at Elevated Temperatures," 2016.

[13] J. Samuels and S. G. Roberts, "The Brittle-Ductile Transition in Silicon. I. Experiments," Proc. R. Soc. A Math. Phys. Eng. Sci., vol. 421, no. 1860, pp. 1-23, 1989.

[14] D. E. J. Armstrong and E. Tarleton, "Bend Testing of Silicon Microcantilevers from 21 ${ }^{\circ} \mathrm{C}$ to $770^{\circ}$ C,” Jom, vol. 67, no. 12, pp. 2914-2920, 2015.

[15] E. D. Hintsala, S. Bhowmick, X. Yueyue, R. Ballarini, S. A. S. Asif, and W. W. Gerberich, "Temperature dependent fracture initiation in microscale silicon," Scr. Mater., vol. 130, pp. 78-82, 2017. 
[16] J. D. Murphy, A. Giannattasio, Z. Yao, C. J. D. Hetherington, P. D. Nellist, and S. G. Roberts, "The mechanical properties of tungsten grown by chemical vapour deposition,” J. Nucl. Mater., vol. 386-388, pp. 583-586, 2009.

[17] Y. Zhang, A. V Ganeev, J. Tao, J. Qiang, and I. V Alexandrov, "Observations on the ductile-to-brittle transition in ultrafine-grained tungsten of commercial purity," vol. 503, pp. 37-40, 2009.

[18] J. Riedle, P. Gumbsch, and H. F. Fischmeister, "Cleavage Anisotropy in Tungsten Single Crystals,” Phys. Rev. Lett., vol. 76, no. 19, pp. 3594-3597, 1996.

[19] B.-S. Li, T. J. Marrow, S. G. Roberts, and D. E. J. Armstrong, "Evaluation of Fracture Toughness Measurements Using Chevron-Notched Silicon and Tungsten Microcantilevers," JOM, 2019.

[20] S. Wurster, B. Gludovatz, A. Hoffmann, and R. Pippan, "Fracture behaviour of tungsten - vanadium and tungsten - tantalum alloys and composites," J. Nucl. Mater., vol. 413, pp. 166-176, 2011.

[21] P. B. Hirsch, A. S. Booth, M. Ellis, and S. G. Roberts, "Dislocation-driven stable crack growth by microcleavage in semi-brittle crystals," Scr. Metall. Mater., vol. 27, no. 12, pp. 1723-1728, 1992.

[22] B.-S. Li, "Measuring fracture resistance behaviour of tungsten using chevron-notched micro-cantilevers," University of Oxford, 2017. 


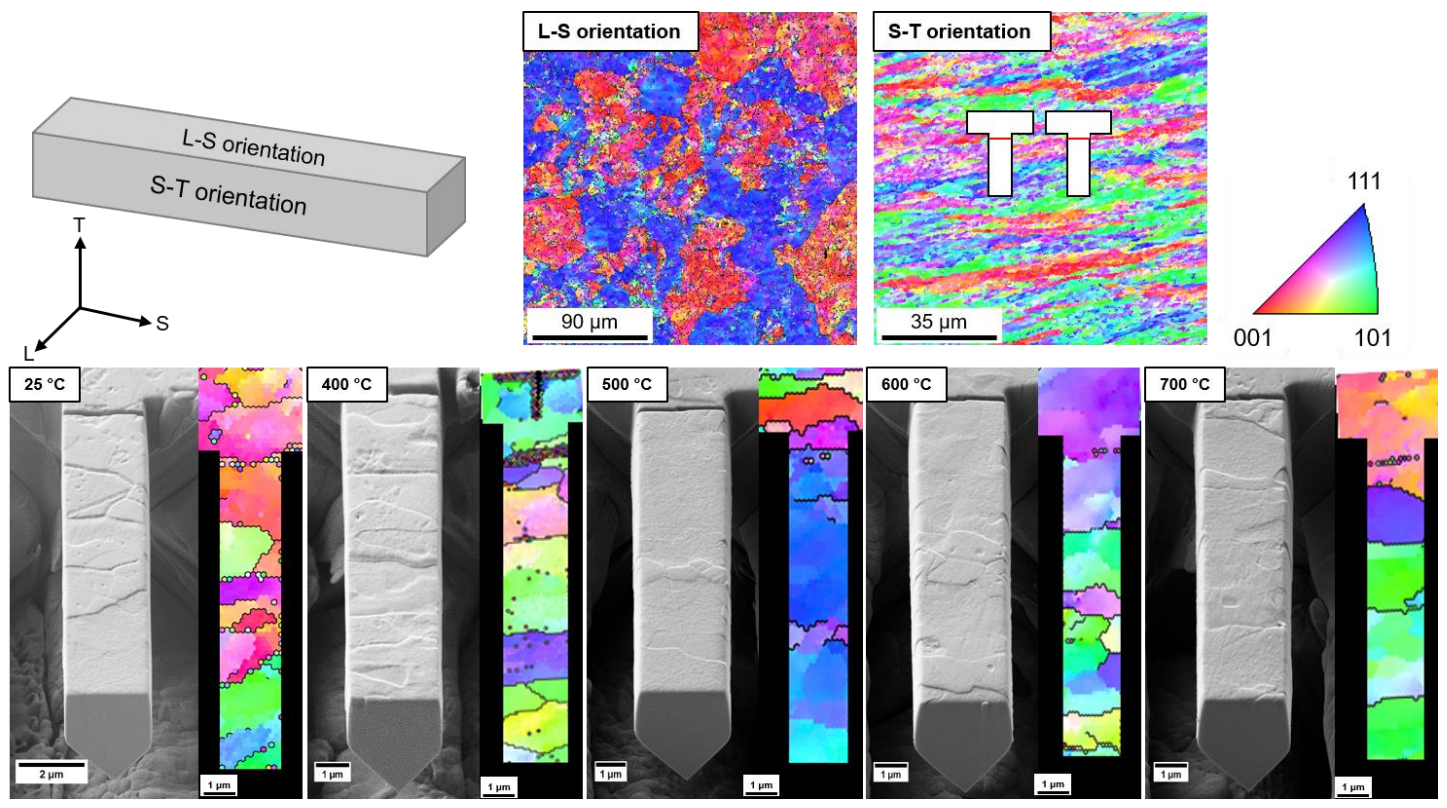

Fig. 1 SEM images and EBSD maps of the W-1\% Ta chevron-notched micro-cantilevers. The polycrystalline cantilevers are fabricated on the S-T orientation, and the colour gradients within grains indicate the high dislocation density from the hot forging process.
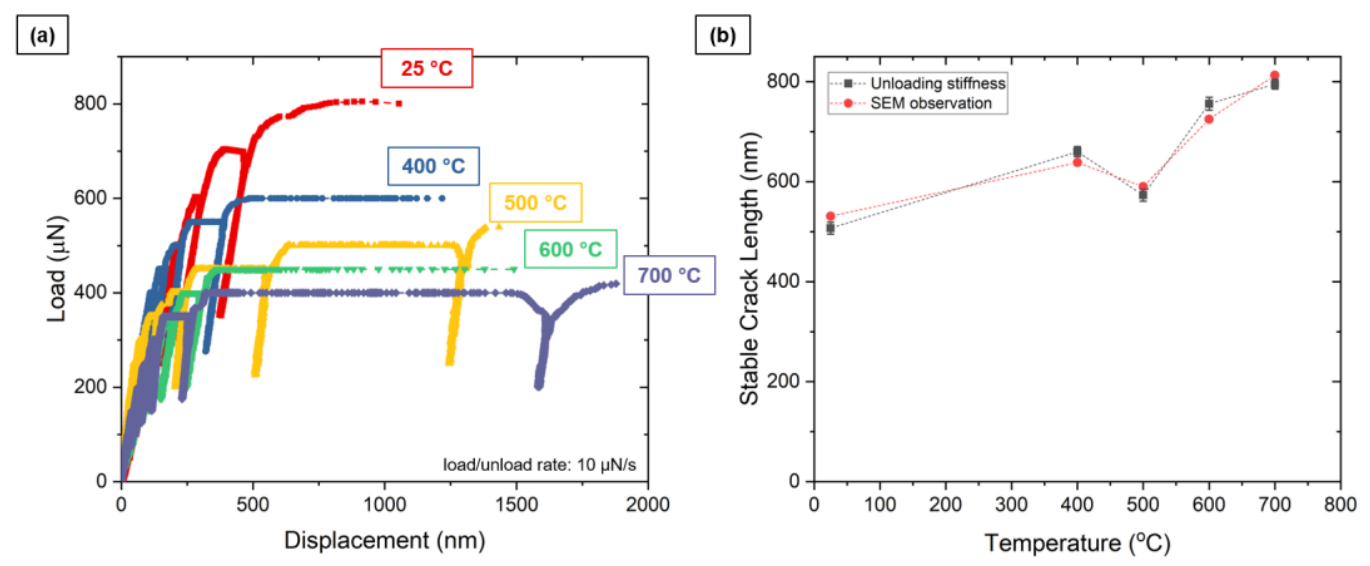

Fig. 2(a) Load-displacement curves of the W-1\% Ta cantilevers tested from 25 to $700{ }^{\circ} \mathrm{C}$, and (b) stable crack length measured from unloading stiffness and post-test SEM fractography 


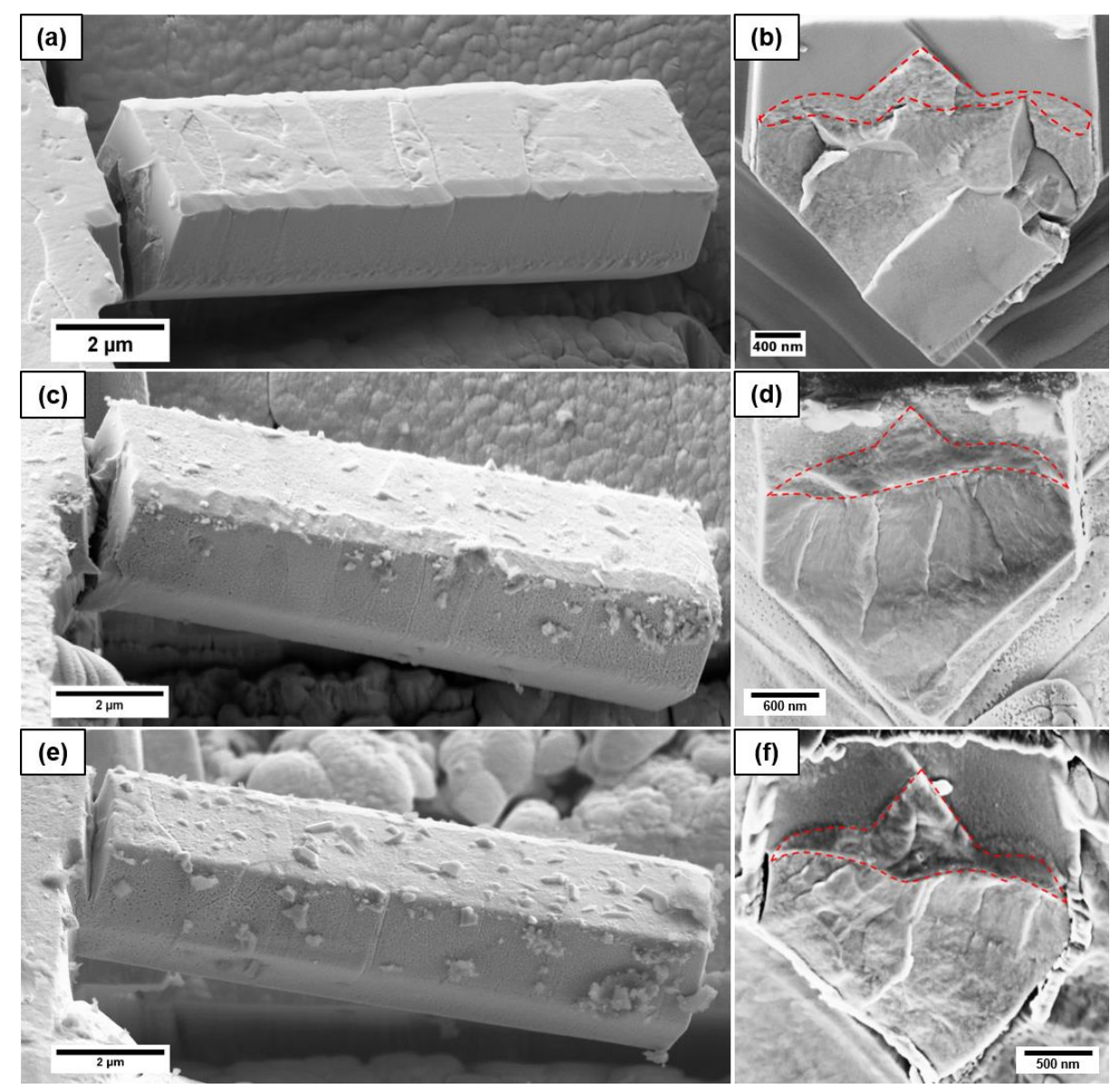

Fig. 3(a) (b) Post-test SEM images and fracture surfaces of cantilevers tested at $25^{\circ} \mathrm{C}$, (c) $\sim\left(\right.$ d) tested at $600{ }^{\circ} \mathrm{C}$, and (e) (f) tested at $700{ }^{\circ} \mathrm{C}$ 


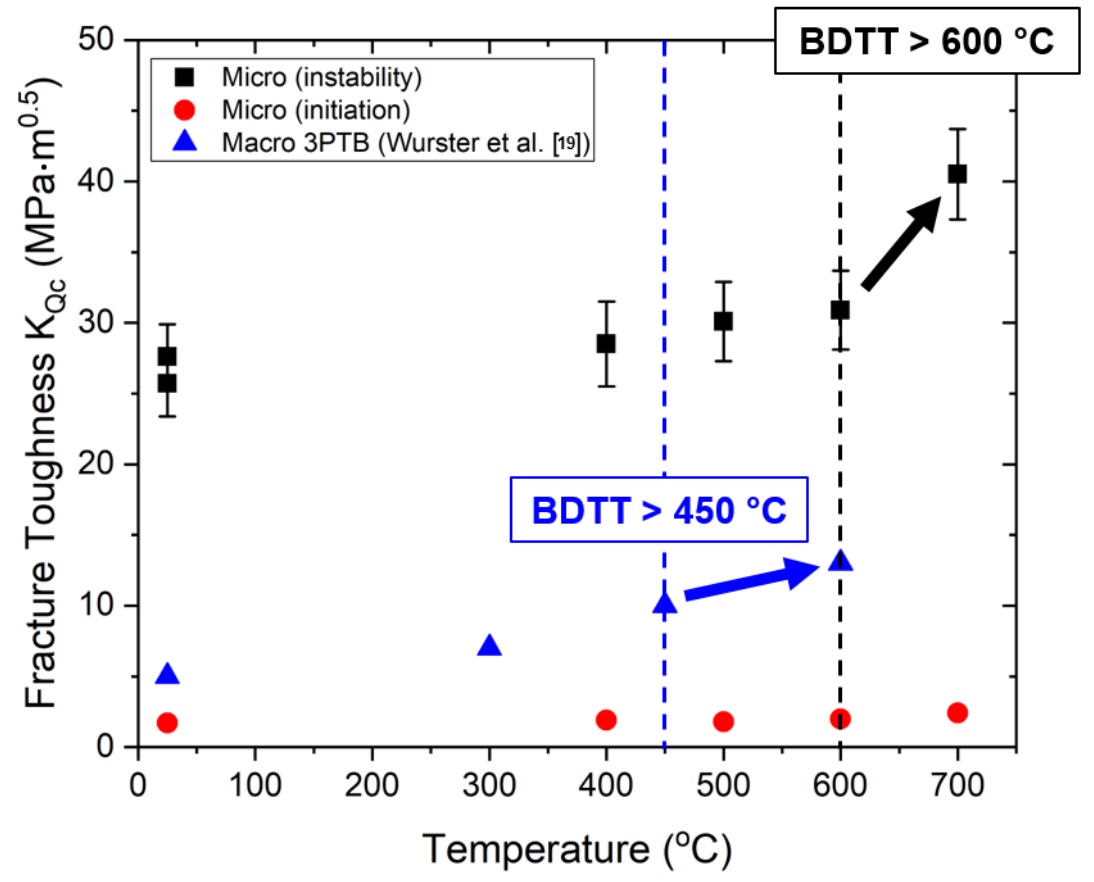

Fig. 4 Fracture toughness $\left(\mathrm{K}_{\mathrm{Qi}}\right.$ and $\left.\mathrm{K}_{\mathrm{Qc}}\right)$ as function of temperature for both W-1\% Ta microcantilevers and 3-PTB matchsticks [20]. A gradual increase of toughness with temperature was observed, and a BDTT $\sim 600{ }^{\circ} \mathrm{C}$ was reported from the micro-cantilever tests, and $\sim 450^{\circ} \mathrm{C}$ from the macroscopic 3-PTB tests 